\title{
Effects of silencing S100A8 and S100A9 with small interfering RNA on the migration of CNE1 nasopharyngeal carcinoma cells
}

\author{
LIN-LIN YAN ${ }^{1}$, YUAN-JIAO HUANG $^{1}$, XIANG YI $^{2}$, XUE-MIN YAN $^{1}$, YAN CAI $^{1}$, QIN HE$^{1}$ and ZI-JIAN HAN ${ }^{1}$ \\ ${ }^{1}$ Medical Scientific Research Center, Guangxi Medical University; ${ }^{2}$ Department of Otolaryngology - Head and Neck Surgery, \\ First Affiliated Hospital of Guangxi Medical University, Nanning, Guangxi 530021, P.R. China
}

Received December 26, 2014; Accepted March 2, 2015

DOI: $10.3892 / 01.2015 .3090$

\begin{abstract}
The calcium-binding S100 proteins are involved in functions such as cell growth, differentiation, migration, adhesion and signal transduction. S100A8 and S100A9 are highly expressed in a variety of tumor cells, and are implicated in tumor development and progression. However, the role of S100A8 and S100A9 in nasopharyngeal carcinoma (NPC) cell migration is unclear. The present study investigated the effect of S100A8 and S100A9 on migration using a NPC cell line, CNE1. The CNE1 cells were transfected with S100A8 or S100A9 small interfering RNA (siRNA). Reverse transcription-quantitative polymerase chain reaction (RT-qPCR) was used to detect S100A8 and S100A9 gene expression. Following the downregulation of S100A8 or S100A9, the effects on cell migration were determined using wound-healing assays. The expression of matrix metalloproteinase-7 (MMP7), a member of the MMP family that is associated with tumor cell invasion and migration, was also detected by RT-qPCR. S100A8 and S100A9 siRNAs effectively suppressed S100A8 and S100A9 gene expression, and substantially inhibited the migration of the CNE1 cells. In addition, MMP7 expression was reduced to varying extents in S100A8 and S100A9 siRNA-treated cells compared with controls. Thus, S100A8 and S100A9 promoted the migration of CNE1 NPC cells.
\end{abstract}

\section{Introduction}

Nasopharyngeal carcinoma (NPC) is a type of malignant tumor derived from nasal epithelial cells (1), and is one of the

Correspondence to: Dr Yuan-Jiao Huang, Medical Scientific Research Center, Guangxi Medical University, 22 Shuangyong Street, Nanning, Guangxi 530021, P.R. China

E-mail: hyjgxmu@126.com

Abbreviations: siRNA, small interfering RNA; RT-qPCR, real-time quantitative polymerase chain reaction; NPC, nasopharyngeal carcinoma; MMPs, matrix metalloproteinases

Key words: nasopharyngeal carcinoma, small interfering RNA, S100A8, S100A9, migration most common malignancies in Southern China and Southeast Asia (2-4), with an incidence rate of 20-30 per 100,000 individuals $(2,5,6)$. NPCs frequently go unnoticed by patients as pathogenic locations are difficult to detect, primary lesions are small and symptoms are mild. The biological characteristics and abundant peripheral lymphoid tissue involvement of NPC make this malignancy more prone to metastasis and invasion compared with other head and neck tumors. Partial recurrence and distant metastasis of NPC are causes of treatment failure (7). Consequently, the majority of patients succumb to the effects of tumor metastasis rather than to the primary lesion. Research on the invasion and migration of NPC is therefore essential.

S100A8 protein (also known as calgranulin A or MRP8 protein) and S100A9 protein (also known as calgranulin B or MRP14 protein) are members of the S100 calcium-binding protein family and usually form a calcium-dependent S100A8/A9 heterodimer complex (8-10). S100A8/A9 is predominantly located in the cytoplasm, with some localized to the nucleus. The complex is normally expressed in circulating neutrophils and monocytes, and marrow cells in early differentiation, with no expression in tissue macrophages. S100A8/A9 is primarily expressed in well-differentiated tissue cells, including epithelial and skin cells (11). A number of studies have suggested that S100A8/A9 expression is upregulated in a variety of primary and invasive tumors $(12,13)$. Kim et al (14) reported increased expression of S100A8/A9 in colorectal carcinoma tissues and serum in patients with early colorectal cancer. Hermani et al (15) demonstrated that the expression level of S100A8/A9 in prostatic intraepithelial neoplasia and prostatic adenocarcinoma is higher compared with that of benign prostate hyperplasia tissues. In addition, the serum level of S100A9 in patients with prostate cancer is higher than in patients with benign prostatic hyperplasia or in healthy subjects.

Saha et al (16) reported that treating B6F10 melanoma cells with $\mathrm{S} 100 \mathrm{~A} 8 / \mathrm{A} 9$ at $0.2-1 \mu \mathrm{g} / \mathrm{ml}$ induces expression of matrix metalloproteinases (MMPs), which are involved in the invasion and migration of tumor cells, promoting cell migration. In a study on endogenous S100A8/A9, Yong and Moon (17) reported that S100A8/A9 secreted by tumor cells causes cell invasion and migration.

In another previous study, the plasma concentration of S100A8 and S100A9 in NPC patients was higher than in healthy subjects, as indicated by isobaric tags for relative and 
absolute quantitation combined with two-dimensional liquid chromatography/tandem mass spectrometry (18). The present study aimed to clarify the effects on CNE1 NPC cell migration following knockdown of S100A8 and S100A9 with small interfering RNA (siRNA).

\section{Materials and methods}

Cell lines and cell culture. The CNE1 NPC cell line was obtained from the Cell Collection of the Central South University Xiangya Central Laboratory (Changsha, Hunan, China). The cells were maintained in RPMI-1640 culture medium (Hyclone, Logan, UT, USA) supplemented with $10 \%$ fetal bovine serum (FBS; Hyclone), $100 \mathrm{U} / \mathrm{ml}$ penicillin and $100 \mu \mathrm{g} / \mathrm{ml}$ streptomycin in a humidified atmosphere of $5 \% \mathrm{CO}_{2}$ at $37^{\circ} \mathrm{C}$. The cells were subcultured every three days, and cells in the logarithmic growth phase were used for the experiments.

Design and synthesis of S100A8 and S100A9 siRNAs. SiRNA sequences for S100A8 and S100A9 gene silencing were designed according to mRNA sequences (S100A8 NCBI Reference Sequence, NM_002964.4; S100A9 NCBI Reference Sequence, NM_002965.3). The siRNA sequences with S100A8 and S100A9 target sites, in addition to the negative control siRNA sequences (Shanghai GenePharma Co., Ltd., Shanghai, China) are listed in Table I.

Cell transfection. To determine the transfection efficiency prior to interference experiments, a negative control siRNA with green fluorescence was transfected into the CNE1 cells. The conditions for optimal transfection efficiency were determined by calculating the percentage of fluorescent cells using a fluorescence microscope and optimizing the ratio of Lipofectamine 2000 transfection reagent (Invitrogen Life Technologies, Carlsbad, CA, USA) to siRNA. The cells were divided into five groups: Experimental S100A8 group transfected with siRNA; experimental S100A9 group transfected with siRNA; blank control group containing untreated cells; negative control group transfected with non-targeting control siRNA; and mock-treatment group treated with transfection reagent only. Results were obtained by the comparative analysis of experimental groups to control groups. The CNE1 cells in each group were seeded into six-well plates at a density of $3 \times 10^{5}$ cells/well in RPMI-1640 medium containing 10\% FBS without antibiotics for $24 \mathrm{~h}$. The cells were transfected with siRNA in serum-free RPMI-1640 medium, following the manufacturer's instructions for the use of Lipofectamine 2000. Following incubation at $37^{\circ} \mathrm{C}$ in an atmosphere of $5 \% \mathrm{CO}_{2}$ for $6 \mathrm{~h}$, the medium was replaced with RPMI-1640 medium supplemented with $10 \%$ serum, and the cells were incubated for $24 \mathrm{~h}$ prior to use.

Detection of S100A8 and S100A9 expression by reverse transcription-quantitative polymerase chain reaction ( $R T-q P C R)$. Total RNA was isolated from the cells using total RNA extraction kits (Corning Life Sciences, Axygen ${ }^{\circledR}$ Inc., Union City, CA, USA), and RNA integrity and concentration were determined by spectrophotometry $\left(\mathrm{OD}_{260} / \mathrm{OD}_{280}\right.$ value, 1.9 ; concentration, $980 \mathrm{ng} / \mu \mathrm{l})$. cDNA was obtained using reverse transcription kits
(Takara Biotechnology Co., Ltd., Dalian, China) following the removal of genomic DNA. qPCR was performed using SYBR Green master mix (Roche Applied Science, Penzberg, Upper Bavaria, Germany) and Mastercycler ${ }^{\circledR}$ ep realplex (Eppendorf, Hauppauge, NY, USA). Primer sequences for S100A8, S100A9 and $\beta$-actin are listed in Table II. The relative expression level was normalized to $\beta$-actin. Experiments were performed in triplicate with a no-template control. PCR conditions were as follows: $95^{\circ} \mathrm{C}$ for $10 \mathrm{~min}$, followed by 40 cycles of $15 \mathrm{sec}$ at $95^{\circ} \mathrm{C}$ and $60 \mathrm{sec}$ at $60^{\circ} \mathrm{C}$. S100A8-Homo-374 siRNA and S100A9-Homo-267 siRNA were used in the experiments, as they were identified to be the most effective for interference based on multiple comparisons among the siRNAs for the three groups.

Cell migration assays. Cell migration was determined using scratch wound-healing assays. Five equally spaced lines were made on the backs of six-well plates, and the cells were seeded at a density of $3 \times 10^{5}$ cells/well. Cells were transfected, and after $24 \mathrm{~h}$, a sterile $200-\mu \mathrm{l}$ pipette tip was used to scratch the cells perpendicular to the lines to form a wound. The cells were washed three times with phosphate-buffered saline to remove dead cells and cultured with serum-free medium. Width values from at least three scratches were then measured at more than three positions per scratch. Images were captured at $0,24,48$ and $72 \mathrm{~h}$ after the scratches were made. The width of scratches was measured at each time-point to compare migration ratios among the groups.

Detection of MMP7 expression by RT-qPCR. The primers used to detect MMP7 are listed in Table II. The detection method used was the same as that used for the detection of S100A8 and S100A9 expression.

Statistical analysis. Statistical analyses were conducted using SPSS version 16.0 (SPSS, Inc., Chicago, IL, USA). Data are presented as the mean \pm standard deviation, and significance was determined by one-way analysis of variance (ANOVA); multiple comparisons between two groups were determined by a least significant difference analysis in the ANOVA. $\mathrm{P}<0.05$ was considered to indicate a statistically significant difference.

\section{Results}

Detection of fluorescence in transfected cells. The cells were observed under a fluorescence microscope. The CNE1 cells transfected with the negative control siRNA exhibited a green fluorescence (Fig. 1), whilst untransfected cells did not. Transfection efficiencies were high using transfection agent to siRNA ratios of 1:2 and 1:3; a ratio of 1:2 was selected for use in subsequent transfections. Five randomly selected fields of x20 magnification revealed $\sim 80 \%$ of cells with fluorescence, indicating the successful transfection of the siRNA.

Interference effects of S100A8 and S100A9 siRNAs. The relative expression of S100A8 was 0.16 , which was significantly lower compared with that of the blank control, negative control and mock-treatment groups $(\mathrm{F}=69.95, \mathrm{P}<0.01)$. No significant difference was observed among the blank control, negative control and mock-treatment groups ( $\mathrm{P}>0.05$; Fig. 2A). The relative expression of S100A9 was 0.26 , and was significantly 
Table I. Small interfering RNA sequences used for cell transfection.

\begin{tabular}{lcc}
\hline Group & Sense & Antisense \\
\hline S100A8-Homo-286 & 5'-AGACCGAGUGUCCUCAGUA-3' & 5'-UACUGAGGACACUCGGUCU-3' \\
S100A8-Homo-324 & 5'-GACGUCUGGUUCAAAGAGU-3' & 5'-ACUCUUUGAACCAGACGUC-3' \\
S100A8-Homo-374 & 5'-CCAGGAGUUCCUCAUUCUG-3' & 5'-CAGAAUGAGGAACUCCUGG-3' \\
S100A9-Homo-61 & 5'-GCAGCUGGAACGCAACAUA-3' & 5'-UAUGUUGCGUUCCAGCUGC-3' \\
S100A9-Homo-100 & 5'-CCACCAAUACUCUGUGAAG-3' & 5'-CUUCACAGAGUAUUGGUGG-3' \\
S100A9-Homo-267 & 5'-GCUUCGAGGAGUUCAUCAU-3' & 5'-AUGAUGAACUCCUCGAAGC-3" \\
Negative control & 5'-GCGACGAUCUGCCUAAGAU-3' & 5'-AUCUUAGGCAGAUCGUCGC-3"
\end{tabular}

Table II. Primer sequences used in reverse transcription-quantitative polymerase chain reaction experiments.

\begin{tabular}{lll}
\hline Gene & \multicolumn{1}{c}{ Sense } & \multicolumn{1}{c}{ Antisense } \\
\hline S100A8 & 5'-GCTAGAGACCGAGTGTCCTCAG-3' & 5'-GCCCATCTTTATCACCAGAATG-3' \\
S100A9 & 5'-TGGAGGACCTGGACACAAATG-3' & 5'-TCGTCACCCTCGTGCATCTT-3 \\
3-actin & 5'-CAGGCACCAGGGCGTGAT-3' & 5'-TAGCAACGTACATGGCTGGG-3' \\
Matrix metalloproteinase-7 & 5'-GGAACAGGCTCAGGACTATCTC-3' & 5'-CAACATCTGGCACTCCACA-3' \\
\hline
\end{tabular}
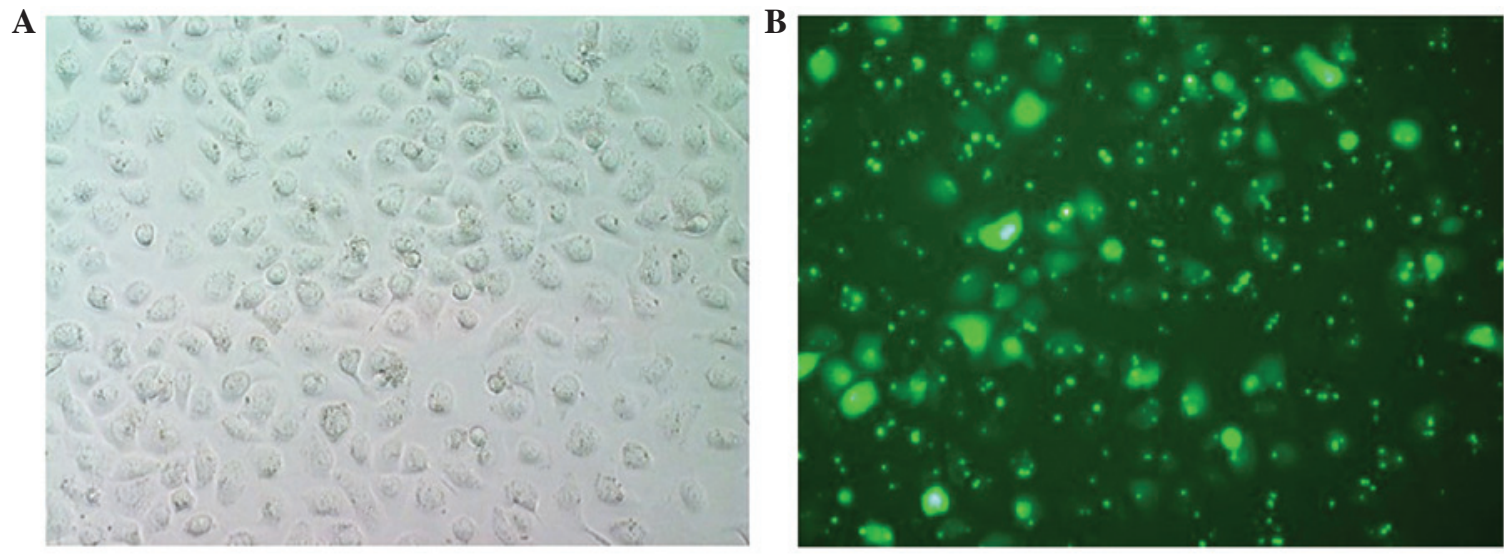

Figure 1. Fluorescence detection of transfected cells. (A) CNE1 cells were observed under bright field microscopy. (B) Negative control small interfering RNA with green fluorescence was successfully transfected into the CNE1 cells.
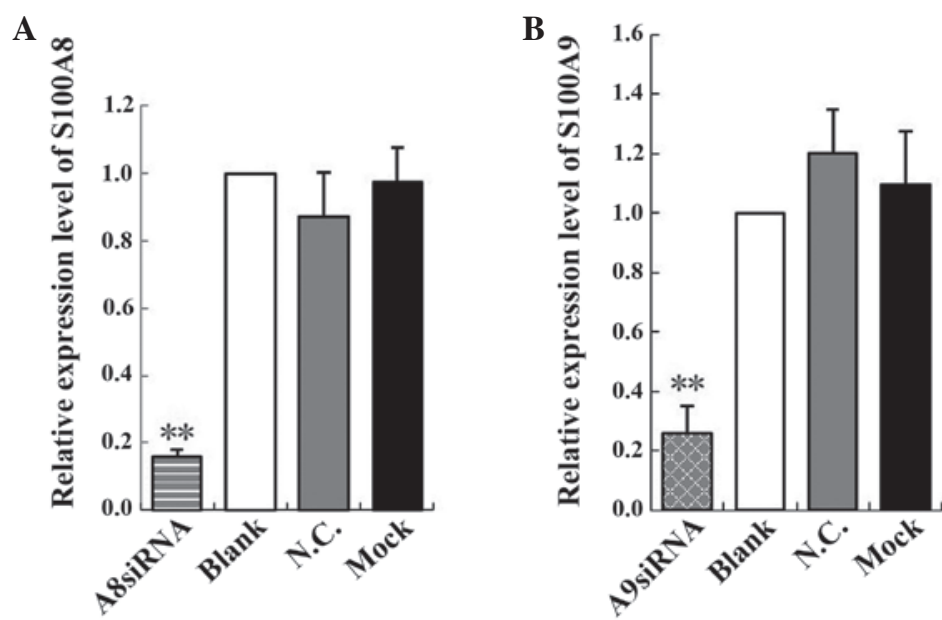

Figure 2. Relative expression of (A) S100A8 and (B) S100A9 detected by reverse transcription-quantitative polymerase chain reaction. ${ }^{* *} \mathrm{P}<0.01$ vs. blank control, negative control and mock-treatment groups. Bars indicate the mean \pm standard deviation from three independent experiments. A8 siRNA, S100A8 siRNA; A9 siRNA, S100A9 siRNA; Blank, untreated CNE1 cells; N.C., negative control siRNA; Mock, transfection reagent only. 
0

A
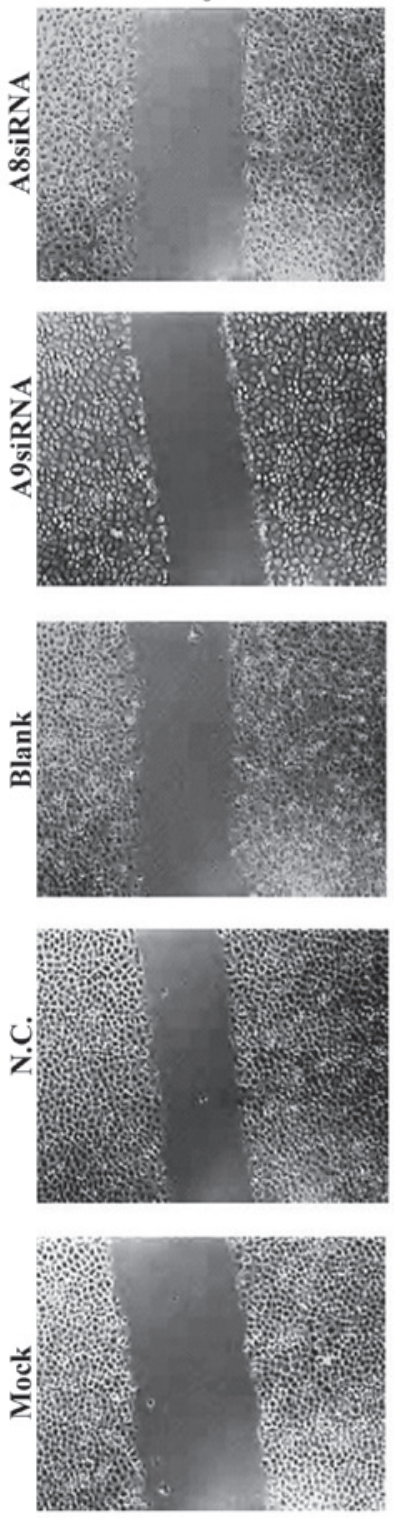

24
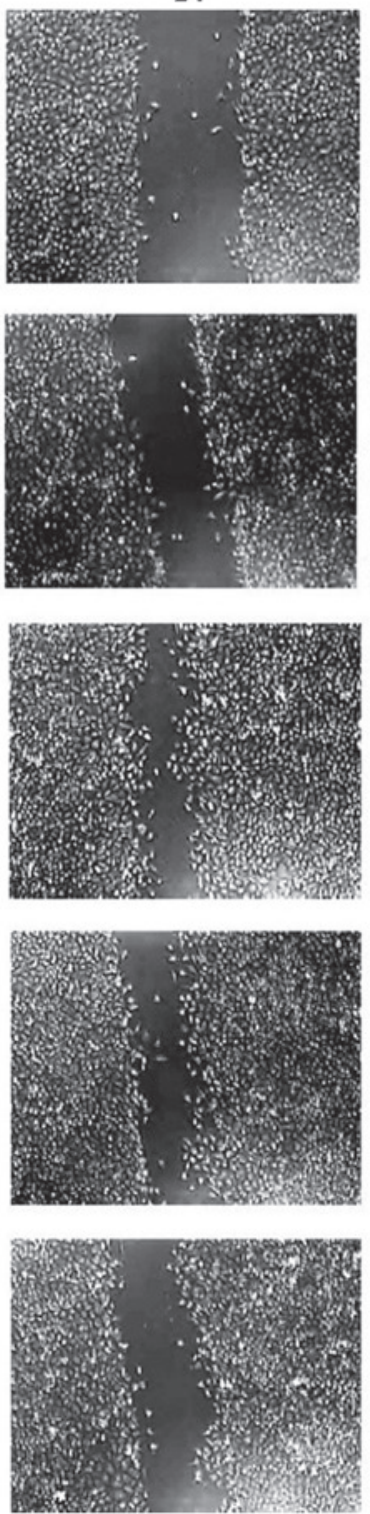

48
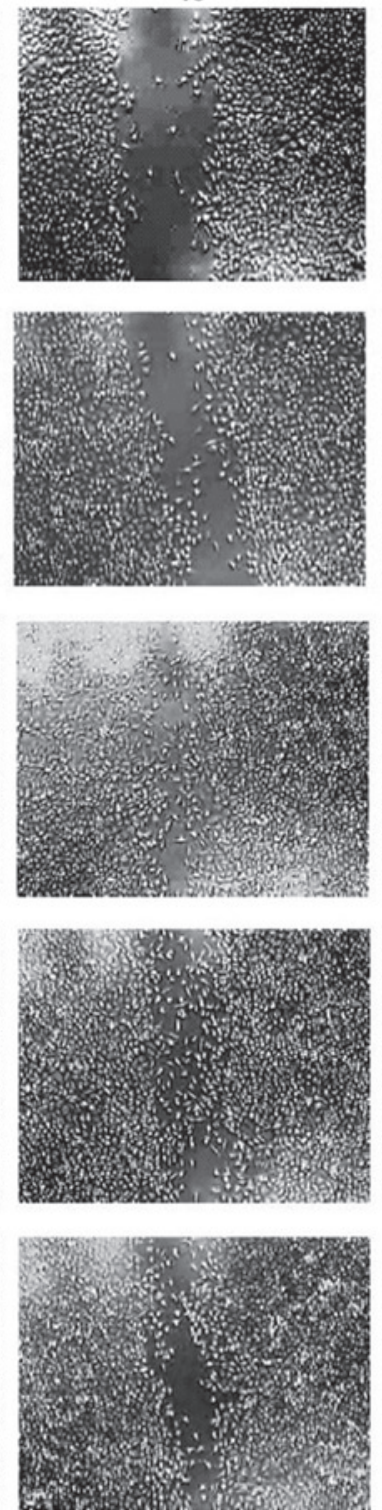

72
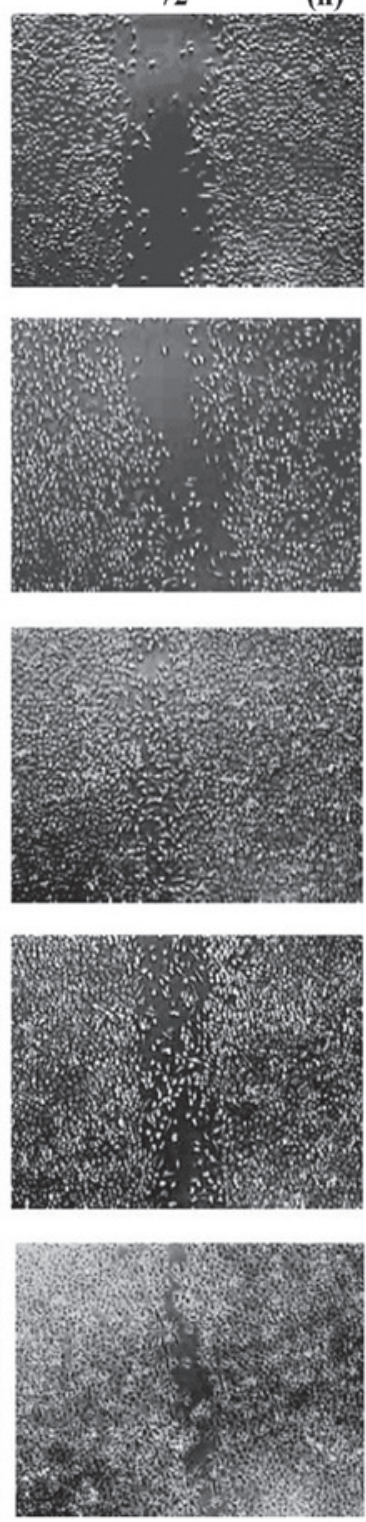

口A8siRNA

口A9siRNA

Dlank

口N.C.

Mock

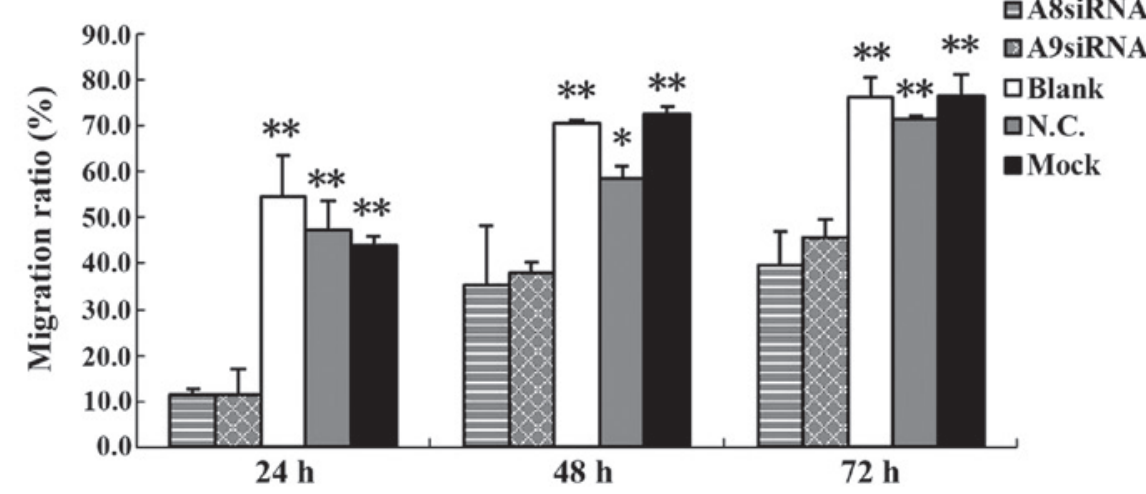

Figure 3. Effects of S100A8 and S100A9 siRNAs on CNE1 cell migration. (A) Images of scratch wound healing assays were captured under a microscope. (B) Comparisons of migration ratio per group by time-point. ${ }^{* *} \mathrm{P}<0.01$ vs. S100A8 siRNA and S100A9 siRNA groups, ${ }^{2} \mathrm{P}<0.05$ vs. S100A8 siRNA and S100A9 siRNA groups. Bars indicate the mean \pm standard deviation from three independent experiments. A8 siRNA, S100A8 siRNA; A9 siRNA, S100A9 siRNA; Blank, untreated CNE1 cells; N.C., negative control siRNA; Mock, transfection reagent only.

lower compared with that of the blank control, negative control and mock-treatment groups $(\mathrm{F}=34.91, \mathrm{P}<0.01)$. No significant difference was observed among the blank control, negative control and mock-treatment groups ( $\mathrm{P}>0.05$; Fig. 2B). These results indicated that the S100A8 and S100A9 siRNAs effectively inhibited S100A8 and S100A9 expression. 
Table III. Migration ratio of each group in scratch wound healing assays.

\begin{tabular}{lccc}
\hline & \multicolumn{3}{c}{ Migration ratio, $\%$} \\
\cline { 2 - 4 } Group & $24 \mathrm{~h}$ & $48 \mathrm{~h}$ & $72 \mathrm{~h}$ \\
\hline S100A8 siRNA & $11.41 \pm 1.30$ & $35.27 \pm 13.03$ & $39.57 \pm 7.29$ \\
S100A9 siRNA & $11.53 \pm 5.50$ & $37.99 \pm 2.28$ & $45.71 \pm 4.04$ \\
Blank & $54.61 \pm 8.87$ & $70.64 \pm 0.66$ & $76.06 \pm 4.49$ \\
Negative control & $47.36 \pm 6.32$ & $58.59 \pm 2.69$ & $71.45 \pm 0.79$ \\
Mock & $43.83 \pm 2.22$ & $72.71 \pm 1.58$ & $76.67 \pm 4.55$ \\
F-value & 27.56 & 16.88 & 28.64 \\
P-value & 0.001 & 0.004 & 0.001 \\
\hline
\end{tabular}

F- and P-values were determined by one-way analysis of variance. siRNA, small interfering RNA.

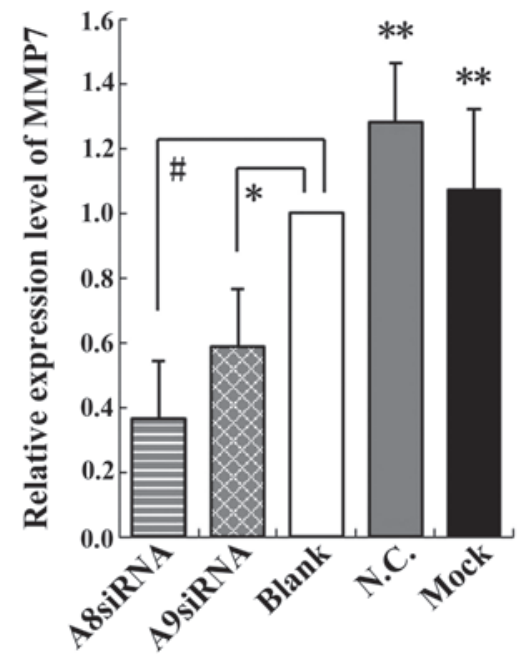

Figure 4. Effects of S100A8 and S100A9 siRNA on MMP7 expression in CNE1 cells. Relative expression of MMP7 was determined by reverse transcription-quantitative polymerase chain reaction. Relative band intensities were quantitated. ${ }^{\#} \mathrm{P}<0.01 ;{ }^{*} \mathrm{P}<0.05 ;{ }^{* *} \mathrm{P}<0.01$ vs. S100A8 siRNA and S100A9 siRNA groups. Bars represent the mean \pm standard deviation from three independent experiments. MMP7, matrix metalloproteinase-7; siRNA, small interfering RNA; A8siRNA, S100A8 siRNA; A9siRNA, S100A9 siRNA; Blank, untreated CNE1 cells; N.C., negative control siRNA; Mock, transfection reagent only.

Effects of S100A8 and S100A9 siRNAs on cell migration. No evident restoration was observed in the experimental groups transfected with S100A8 and S100A9 siRNAs at $24 \mathrm{~h}$ after scratching. By contrast, scratches were narrowed in the blank control, negative control and mock-treatment groups. At $48 \mathrm{~h}$ and $72 \mathrm{~h}$, after the effects of the siRNAs had diminished, cell migration in the S100A8 and S100A9 siRNA-transfected experimental groups were restored to a certain degree, while scratched areas in the blank control, negative control and mock-treatment groups had filled with cells. At each time-point after scratching (24, 48 and $72 \mathrm{~h}$ ), the migration ratio of the S100A8 and S100A9 siRNA-transfected experimental groups was significantly lower compared with that of the blank control, negative control and mock-treatment groups (Tables III and IV). No significant differences were observed among the blank control, negative control and mock-treatment groups (P>0.05; Fig. 3; Tables III and IV).
Table IV.P-values for the difference in migration ratios between each treatment group at 24, 48 and $72 \mathrm{~h}$ after scratching, determined by one-way analysis of variance.

\begin{tabular}{|c|c|c|c|c|c|}
\hline \multirow[b]{2}{*}{ Time } & \multicolumn{5}{|c|}{ P-value } \\
\hline & A8siRNA & A9siRNA & Blank & N.C. & Mock \\
\hline \multicolumn{6}{|l|}{$24 \mathrm{~h}$} \\
\hline A8siRNA & - & 0.984 & 0.001 & 0.001 & 0.002 \\
\hline A9siRNA & 0.984 & - & 0.001 & 0.001 & 0.002 \\
\hline Blank & 0.001 & 0.001 & - & 0.250 & 0.111 \\
\hline N.C. & 0.001 & 0.001 & 0.250 & - & 0.555 \\
\hline Mock & 0.002 & 0.002 & 0.111 & 0.555 & - \\
\hline \multicolumn{6}{|l|}{$48 \mathrm{~h}$} \\
\hline A8siRNA & - & 0.674 & 0.002 & 0.012 & 0.002 \\
\hline A9siRNA & 0.674 & - & 0.003 & 0.020 & 0.002 \\
\hline Blank & 0.002 & 0.003 & - & 0.104 & 0.748 \\
\hline N.C. & 0.012 & 0.020 & 0.104 & - & 0.068 \\
\hline Mock & 0.002 & 0.002 & 0.748 & 0.068 & - \\
\hline \multicolumn{6}{|l|}{$72 \mathrm{~h}$} \\
\hline A8siRNA & - & 0.249 & 0.001 & 0.001 & 0.001 \\
\hline A9siRNA & 0.249 & - & 0.001 & 0.003 & 0.001 \\
\hline Blank & 0.001 & 0.001 & - & 0.373 & 0.902 \\
\hline N.C. & 0.001 & 0.003 & 0.373 & - & 0.318 \\
\hline Mock & 0.001 & 0.001 & 0.902 & 0.318 & - \\
\hline
\end{tabular}

A8siRNA, S100A8 siRNA-treated;A9siRNA, S100A9siRNA-treated; Blank, untreated; N.C., negative control siRNA-treated; Mock, transfection reagent only; -, not applicable.

This result indicated that the expression of S100A8 and S100A9 was downregulated by the siRNAs, and that the migration of the CNE1 NPC cells had decreased.

Impact of S100A8 and S100A9 siRNAs on MMP7 expression. The relative expression of MMP7 was 0.3643 for the S100A8 siRNA group and 0.5864 for the S100A9 siRNA group when compared simultaneously with that of the blank control, 
negative control and mock-treatment groups $(\mathrm{F}=13.193$, $\mathrm{P}<0.01)$; no significant differences were observed among the controls ( $\mathrm{P}>0.05 ;$ Fig. 4). These results indicated that inhibition of MMP7 by S100A8 siRNA was more effective than inhibition by S100A9 siRNA. Following the knockdown of S100A8 and S100A9, the expression of MMP7 was downregulated to different extents compared with the control groups.

\section{Discussion}

S100A8/A9 has a strong chemotactic effect on leukocytes surrounding inflammatory lesions, which produce inflammatory cytokines of neutrophils in inflammatory disease. Hermani et al (19) reported that S100A8/A9at $10 \mu \mathrm{g} / \mathrm{ml}$ promotes migration of PNT1A prostate cells. Hiratsuka et al (20) demonstrated that $\mathrm{S} 100 \mathrm{~A} 8 / \mathrm{A} 9$ at extremely low concentrations (S100A8 at $100 \mathrm{pg} / \mathrm{ml}$ and S100A9 at $1 \mathrm{ng} / \mathrm{ml}$ ) promotes the migration of Lewis lung carcinoma and B16 melanoma cells. Mounting evidence indicates that MMP family members are involved in tumor invasion and metastasis (17). MMPs are proteolytic enzymes capable of degrading extracellular matrix proteins (21), whose activity is implicated in a number of key normal and pathological processes, including tumor growth, progression, and metastasis and dysregulated angiogenesis (22). Enzymatic degradation of the extracellular matrix is a crucial step in cancer invasion and metastasis. Another previous study supports the hypothesis that S100A8 is more closely associated with MMP9 expression mediated by the extracellular-signal-regulated kinase pathway, whilst S100A9 has a major role in MMP2 upregulation that is dependent on p38 mitogen-activated protein kinase (MAPK) signaling (23). A further study reported that S100A8 and S100A9 contribute to colorectal carcinoma cell survival and migration via the Wnt/ $\beta$-catenin pathway. S100A8 and S100A9 increase total $\beta$-catenin levels and promote transcription of its target genes (c-myc and MMP7), resulting in the upregulation of the Wnt/ $\beta$-catenin pathway (24).

The present study confirmed that S100A8 and S100A9 is vital for the migration of CNE1 NPC cells, and indicated that MMP7 may be involved. RT-qPCR suggested different inhibitory effects for the three pairs of siRNA sequences for S100A8 and S100A9. The results revealed that S100A8-Homo-374 and S100A9-Homo-267 were the most effective, with inhibition ratios of 84.10 and $74.15 \%$, respectively; these siRNAs were used for subsequent experiments. A previous study indicated that S100A8 and S100A9 were knocked down in SNU484 gastric cancer cells; immunoblot analysis suggested that S100A8 protein levels decreased by $47 \%$ and S100A9 decreased by $85 \%$ (17). Although the S100A8 and S100A9 siRNA sequences used in the previous study differ from those used in the current study, the two siRNA sequences inhibited S100A8 and S100A9 expression effectively.

Scratch wound healing assays performed after different time periods revealed that, according to the migration ratio (Table III), the migration of the CNE1 cells was inhibited by S100A8 siRNA by $88.59 \%$ at 24 h, $64.73 \%$ at $48 \mathrm{~h}$ and $60.43 \%$ at $72 \mathrm{~h}$. Marked inhibition of migration was also observed when S100A9 expression was reduced by siRNA $(88.47 \%$ at $24 \mathrm{~h}$, $62.01 \%$ at $48 \mathrm{~h}$ and $54.29 \%$ at $72 \mathrm{~h}$ ). Moon et al (23) performed Transwell migration assays to demonstrate that $\mathrm{H}$-Ras-mediated human breast epithelial cell migration was inhibited by $57 \%$ by the knockdown of S100A8, and by $80 \%$ by the knockdown of S100A9. Therefore, the scratch wound healing assays and Transwell migration assays illustrated that silencing S100A8 and S100A9 with siRNA inhibits CNE1 cell migration.

In the present study, when MMP7 expression was detected following the application of the most effective siRNAs for S100A8 and S100A9, MMP7 expression was inhibited by $63.57 \%$ in S100A8-downregulated cells and $41.36 \%$ in S100A9-downregulated cells, indicating that the treatment with siRNA for S100A8 exerted a greater inhibitory effect on MMP7 expression compared with that of S100A9. This suggests that S100A8, and to a lesser extent S100A9, may be required for MMP7 expression in CNE1 cells. However, the difference in these results may also be due to greater inhibitory effects of S100A8 siRNA on S100A8 expression, compared with that of S100A9 siRNA on S100A9 expression. Further investigation is required to clarify the differential roles of S100A8 and S100A9 on MMP7 expression in CNE1 cells. Yong and Moon (17) demonstrated that expression level of MMP2 was decreased by $83 \%$ with S100A9 siRNA and by $52 \%$ with S100A8 siRNA, indicating that S100A8/A9 may increase MMP2 and MMP7, although this is inconsistent with the results reported by Kwon et al (21).

In conclusion, the present study demonstrated that the expression of S100A8 and S100A9 was effectively suppressed by siRNA against these two genes, and that the migration of cells was inhibited. In addition, MMP7 expression was somewhat reduced, indicating that endogenous S100A8 and S100A9 promoted the migration of CNE1 NPC cells; this is consistent with the conclusion that S100A8/A9 promotes colon tumor cell metastasis, as reported by Ichikawa et al (25). S100A8 and S100A9 may promote cell migration and invasion through p38 MAPK-dependent nuclear factor- $\kappa \mathrm{B}$ activation (21). Further investigation is required to determine the molecular mechanisms underlying the promotion of CNE1 NPC cell migration by endogenous S100A8 and S100A9.

\section{Acknowledgements}

The present study was supported by grants from the National Natural Science Foundation (no. 81260405), the Natural Science Foundation of Guangxi (no. 2011GXNSFA018233), and the Guangxi Science and Technology Agency project (no. GK2013-A-02-02).

\section{References}

1. Sham JS, Wei WI, Zong YS, Choy D, Guo YQ, Luo Y, Lin ZX and Ng MH: Detection of subclinical nasopharyngeal carcinoma by fibreoptic endoscopy and multiple biopsy. Lancet 335: 371-374, 1990.

2. Chang ET and Adami HO: The enigmatic epidemiology of nasopharyngeal carcinoma. Cancer Epidemiol Biomarkers Prev 15: 1765-1777, 2006.

3. Shin HR, Curado MP, Ferlay J, Heanue M, Edwards B and Storm H: Comparability and Quality of Data. In: Cancer Incidence in Five Continents. Parkin DM and Muir CS (eds). IARC Sci Publ: pp45-173, 1992.

4. Nielsen NH, Mikkelsen F and Hansen JP: Nasopharyngeal cancer in Greenland. The incidence in an Arctic Eskimo population. Acta Pathol Microbiol Scand A 85: 850-858, 1977.

5. Yu MC and Yuan JM: Epidemiology of nasopharyngeal carcinoma. Semin Cancer Biol 12: 421-429, 2002. 
6. Gu AD, Mo HY, Bei JX, Xie YB, Chen LZ, Feng QS, Kang T and Zeng YX: Evaluation of antibodies against different Epstein-Barr virus nuclear antigen 1 peptides in diagnosis of nasopharyngeal carcinoma. Clin Vaccine Immunol 16: 592-593, 2009.

7. Chiesa F and De Paoli F: Distant metastases from nasopharyngeal cancer. ORL J Otorhinolaryngol Relat Spec 63: 214-216, 2001.

8. Korndörfer IP, Brueckner F and Skerra A: The crystal structure of the human (S100A8/S100A9)2 heterotetramer, calprotectin, illustrates how conformational changes of interacting alpha-helices can determine specific association of two EF-hand proteins J Mol Biol 370: 887-898, 2007.

9. Ott HW, Lindner H, Sarg B, Mueller-Holzner E, Abendstein B, Bergant A, Fessler S, Schwaerzler P, Zeimet A, Marth C, et al: Calgranulins in cystic fluid and serum from patients with ovarian carcinomas. Cancer Res 63: 7507-7514, 2003.

10. Donato R: S100: A multigenic family of calcium-modulated proteins of the EF-hand type with intracellular and extracellular functional roles. Int J Biochem Cell Biol 33: 637-668, 2001.

11. Kong JP, Ding F, Zhou CN, Wang XQ, Miao XP, Wu M and Liu ZH: Loss of myeloid-related proteins 8 and myeloid-related proteins 14 expression in human esophageal squamous cell carcinoma correlates with poor differentiation. World J Gastroenterol 10: 1093-1097, 2004.

12. Gebhardt C, Németh J, Angel P and Hess J: S100A8 and S100A9 in inflammation and cancer. Biochem Pharmacol 72: 1622-1631, 2006

13. Salama I, Malone PS, Mihaimeed F and Jones JL: A review of the S100 proteins in cancer. Eur J Surg Oncol 34: 357-364, 2008.

14. Kim HJ, Kang HJ, Lee H, Lee ST, Yu MH, Kim H and Lee C: Identification of S100A8 and S100A9 as serological markers for colorectal cancer. J Proteome Res 8: 1368-1379, 2009.

15. Hermani A, Hess J, De Servi B, et al: Calcium-binding proteins S100A8 and S100A9 as novel diagnostic markers in human prostate cancer. Clin Cancer Res 11: 5146-5152, 2005.

16. Saha A, Lee YC, Zhang Z, Chandra G, Su SB and Mukherjee AB: Lack of an endogenous anti-inflammatory protein in mice enhances colonization of B16F10 melanoma cells in the lungs. J Biol Chem 285: 10822-10831, 2010.
17. Yong $\mathrm{HY}$ and Moon A: Roles of calcium-binding proteins, S100A8 and S100A9, in invasive phenotype of human gastric cancer cells. Arch Pharm Res 30: 75-81, 2007.

18. Han RR, Huang YJ, Chen L, Xiao XL, Yi X, Cai HW and Wu YH Determination of S100A8 and S100A9 protein in plasma of nasopharyngeal carcinoma patients and its clinical significance. Chin J Clin Lab Sci 32: 252-254, 2014 (In Chinese).

19. Hermani A, De Servi B, Medunjanin S, Tessier PA and Mayer D: S100A8 and S100A9 activate MAP kinase and NF-kappaB signaling pathways and trigger translocation of RAGE in human prostate cancer cells. Exp Cell Res 312: 184-197, 2006.

20. Hiratsuka S, Watanabe A, Aburatani H and Maru Y: Tumour-mediated upregulation of chemoattractants and recruitment of myeloid cells predetermines lung metastasis. Nat Cell Biol 8: 1369-1375, 2006.

21. Kwon CH, Moon HJ, Park HJ, Choi JH and Park Y: S100A8 and S100A9 promotes invasion and migration through p38 mitogen-activated protein kinase-dependent NF- $\kappa \mathrm{B}$ activation in gastric cancer cells. Mol Cells 35: 226-234, 2013.

22. Roy R, Yang J and Moses MA: Matrix metalloproteinases as novel biomarkers and potential therapeutic targets in human cancer. J Clin Oncol 27: 5287-5297, 2009.

23. Moon A, Yong HY, Song JI, Cukovic D, Salagrama S, Kaplan D, Putt D, Kim H, Dombkowski A and Kim HR: Global gene expression profiling unveils S100A8/A9 as candidate markers in H-ras-mediated human breast epithelial cell invasion. Mol Cancer Res 6: 1544-1553, 2008.

24. Duan L, Wu R, Ye L, Wang H, Yang X, Zhang Y, Chen X, Zuo G, Zhang Y, Weng Y, et al: S100A8 and S100A9 are associated with colorectal carcinoma progression and contribute to colorectal carcinoma cell survival and migration via Wnt/ $\beta$-catenin pathway. PLoS One 8: e62092, 2013.

25. Ichikawa M, Williams R, Wang L, Vogl T and Srikrishna G: S100A8/A9 activate key genes and pathways in colon tumor progression. Mol Cancer Res 9: 133-148, 2011. 